\title{
3D DIGITIZATION OF COMPLEX EXHIBITION ITEMS (MOUNTED SKELETONS OF DINOSAURS) AND GENERATION OF VIRTUAL REPLICAS FOR BIOMECHANICAL STUDIES
}

\author{
Á. Rodríguez Miranda ${ }^{1}$, J.M. Valle Melón ${ }^{1, *}$, A. Torices ${ }^{2}$, R. Lostado ${ }^{3}$, P. Navarro ${ }^{2}$, G. Elorriaga Agirre ${ }^{1}$, J. Korro Bañuelos ${ }^{1}$, A. \\ Zornoza-Indart ${ }^{4}$ \\ ${ }^{1}$ Laboratory for the Geometric Documentation of Heritage (GPAC - Built Heritage Research Group), University of the Basque \\ Country (UPV/EHU), Vitoria-Gasteiz (Spain) - (alvaro.rodriguezm, jm.valle)@ehu.eus, gelorriaga002@ikasle.ehu.eus, \\ jaionekorro@hotmail.com \\ ${ }^{2}$ Cátedra de Paleontología, University of La Rioja (Spain) - angelica.torices@unirioja.es, pnavalorb@gmail.com \\ ${ }^{3}$ Department of Mechanical Engineering, University of La Rioja (Spain) - ruben.lostado@unirioja.es \\ ${ }^{4}$ Department of Painting. Faculty of Fine Arts, University of the Basque Country (UPV/EHU), Leioa (Spain) - \\ ainara.zornoza@ehu.eus
}

\section{Commission II, WG II/8}

KEY WORDS: 3D digitization, dinosaur bones, biomechanical analysis

\begin{abstract}
:
The work presented here is part of a broader study concerning the biomechanical analysis of the movement of dinosaurs, which will be done by the finite element method (FEM). For this aim, it will be necessary to count on virtual models of the walking system (that is to say, the foot, leg, etc.) and the substrate on which the dinosaur moved. Both kinds of models can be approximately inferred from fossil remains: bones for the former and ichnites (fossil footprints) for the latter. Obviously, there are important challenges in these models, let us see, for example, that a group of fossil bones (probably incomplete and deteriorate) is very far from a walking animal with not only the bones and the articulations but also with flesh, tendons, skin, claws and so on.

In any case, fossil bones are the only material we have to start modelling. Therefore, the first step will be their 3D digitization. As the expected use of the 3D models defines, the technical characteristics that these models need to comply with, the manuscript will reflect on the qualities that the models for biomechanical purposes need, paying attention to the completeness, geometric accuracy and resolution. Moreover, a practical case is presented with a comparison of a scanning technology (fringe projection) and close range photogrammetry in order to model a 2 meters tall leg of a specimen of Edmontosaurus.
\end{abstract}

\section{INTRODUCTION}

Dinosaurs are, probably, the most fascinating extinct fauna. Proofs of that are the many fictional novels, films, video games, toys, etc., that are released every year. However, apart from the leisure, their study is a field of the greatest concern for the knowledge of the evolution of life on Earth and, consequently, the aim of studies of extremely active researchers worldwide.

There is also a third reason that justifies the interest: the undeniable value of the fossil remains -both the ones related to the specimens themselves such as bones or eggs and the ones concerning their behaviour such as the fossil tracks- as part of our natural (and even cultural) heritage. Let us just mention the many museums, exhibitions or sightseeing tours based on this asset.

As part of the heritage, it has to be conveniently documented in order to ensure its proper preservation, study, knowledge and widespread use. Obviously, the three-dimensional geometry is an essential part of this documentation and, in this regard, the techniques of laser scanning and photogrammetry should pay an indispensable role.
Nevertheless, the way of documenting geometrically the remains is not straightforward but highly dependent on the purpose of the products (the 3D models) and the available resources. Indeed, each purpose will have specific requirements regarding the geometric accuracy, resolution, completeness, texturing and so on. Taking all that into account, here the results of a preliminary work about the three dimensional modelling of part of skeletons for biomechanical studies by the Finite Element Method (FEM) are shown. In particular, the study focuses on a group of bones forming an articulated leg from which it will be derived a dynamic virtual model (with not only the bones but also the flesh, skin, claws, etc.) in order to study the footfall action.

In next section, a description of the element that was documented will be presented: a 2 meter tall real-size replica of a leg of a specimen of Edmontosaurus. The replica has all the bones, from the femur to the most-distal phalanges and is located at the Paleontological Centre of Enciso (La Rioja, Spain). Secondly, the paper will deal with the documentation by means of a short-range scanning technique ("Scan in a box" fringe projection system) and convergent photogrammetry. Then, data processing will be tackled and that will give way to expose the characteristics expected for the results that are to be

\footnotetext{
* Corresponding author
} 
used in dynamic testing and, finally, the text will conclude with a reflection on the adaptability of the obtained results to these features.

\section{STATE OF THE ART}

There are many studies concerning or including the 3D digitization of bones, from the point of view of several fields such as the anatomy and health studies, anthropology or archaeology, although they mainly focus on human bones, the analyses of techniques and good practice recommendations are largely exploitable (Ugidos et al., 2018). On the other hand, we also count with specific studies about paleontological remains (and, in particular, on dinosaur skeletons) which provide a complementary insight with regard to the detailed features of this kind of elements. Interesting examples of the use over time of different digitization technologies for paleontological bones, including many laser scanning techniques and close range photogrammetry, can be found in the literature (Wiedemann, et al., 1999; Mallison, 2011; Falkingham, 2012; Gutiérrez-García et al., 2015; Das et al., 2017, Erolin et al., 2017, Valle et al. 2017).

In the present case, the aim of the digitalization is to provide useful 3D models for the biomechanical analyses. In this context, the meshing criteria and the features of the provided meshes regarding to the quality, reliability and size (for not exceeding the computational limits) have been rightly noted (Marcé-Nogue et al., 2015). Actually, for the final system, the characteristics of the mesh will require a thorough analysis; however, this is something that will be tackled in a subsequent phase, when the rest of components (that is to say, the virtual reconstruction of the soft parts of the leg and the ground surface) will also be advanced. For the moment, the main concern lies in testing the possibilities of the different techniques for generating complete 3D models of the bones with different degrees of accuracy and resolution, detecting possible pitfalls and gaining experience with this kind of elements so, at a later stage, there will be the possibility of adjusting the procedure according to the updated needs.

Another essential aspect, also pointed out (e.g. Molnar et al., 2012), is that the original specimens from which the virtual model is to be derived can be incomplete, either because part of the bones are not present or because they are not fully accessible, for instance, due to the fact that they are still partly embedded in the rock (figure 1). Therefore, techniques for extrapolation are to be used in order to provide images of "complete" bones that can be used in subsequent steps.

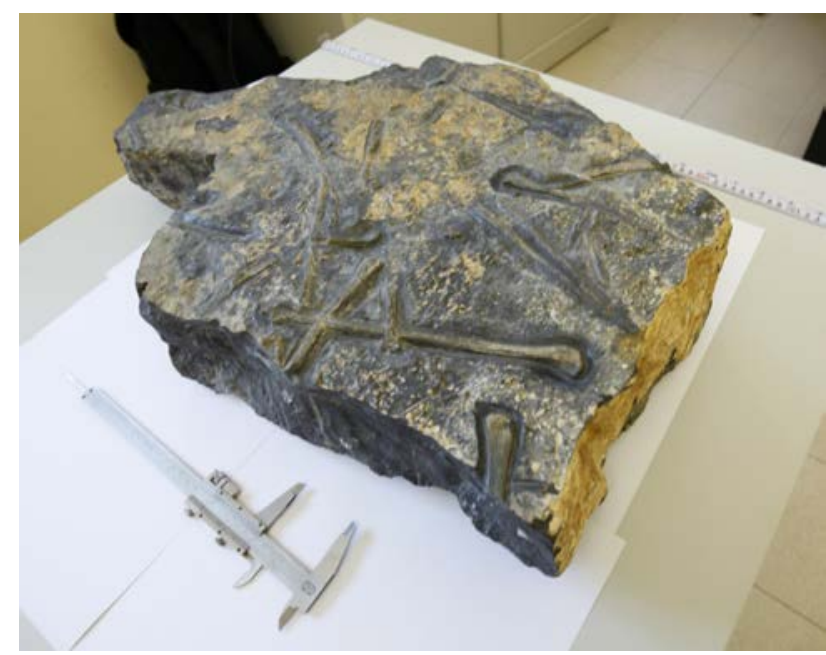

Figure 1. Example of slab with pterosaur bones embedded in the rocky substrate.

\section{MATERIALS AND METHODS}

In the present case study, the element to digitize is a full size replica of a hind leg of Edmontosaurus that is part of the exhibition at the Paleontological Centre in Enciso (La Rioja, Spain). As this was a first attempt in order to test methodologies and define a way of working, the use of this replica seemed adequate. However, for the forthcoming studies we want to apply the lessons learned of this preliminary work to other groups of bones (this time, original ones and for other species of dinosaurs). We need to take into account that the use of real fossils will also require special preventive measurements concerning the handling of them that, for the moment, it is preferable to avoid.

The digitalized material is a complete hind limb replica of Edmontosaurus regalis (Lambe, 1917), specifically of the specimen ROM 801. E. regalis is a North American iguanodontian of the Late Cretaceous. Iguanodontia (Sereno, 1986) was an extremely successful clade, with taxa ranging from Middle Jurassic to Late Cretaceous, with a pancontinental distribution, especially during Cretaceous (Norman et al., 2004). The piece is composed of 18 bones of different size, from the femur of around 1 meter long to the smallest of the phalanxes with a length of $3 \mathrm{~cm}$. It is already mounted in anatomical position, with the knee slightly bended and all the leg leaning forward. The fastening is done by means of metal joints between bones and a metal ring that surrounds and grasps the upper part of the femur. The height above the base surface of the small platform on with it is exhibited is around 1.8 meters.

Initially, we planned to dismount the display and digitize each bone individually. However, once in the Paleontological Centre this proved impossible, hence, we decided to digitize the piece as it was. This situation limited the visibility of several parts of the bones.

We managed to work outside opening hours so we were free to move around the room and set up the equipment (total station, structured-light scanner, computer...) without disturbing the visitors. Besides, we could control lighting conditions; that was particularly interesting for the fringe projection scanning which need to work in the dark. On the contrary, during the photographic record the lights were on, although it has to be 
mentioned that the lights for the exhibition are not adequate for good photographic recording (for 3D modelling) since they are too bright and the set up is designed to seek high contrasts and strong shadows that give a more impressive view of the pieces.

A series of eight methacrylate targets $(2 \mathrm{by} 2 \mathrm{~cm})$ were placed as control points: four around the foot and four on the board. They were given coordinates with a reflectorless total station (precision of around $3 \mathrm{~mm}$ ) (figure 2).

That precision was deemed sufficient for our purpose; however, for more precise requirements it is possible to resort to calibrated scale bars. In any case, although the numeric values of the orientations provided by the photogrammetric software tend to be much better with these scale bars, the usefulness of control point must not be underestimated. In fact, control points provide homogeneous coverage and, hence, give reliable estimations of the precision for the whole 3D model, which is not always the case when using scale bars (in particular, when the bar is relatively small compared to the element to be documented).

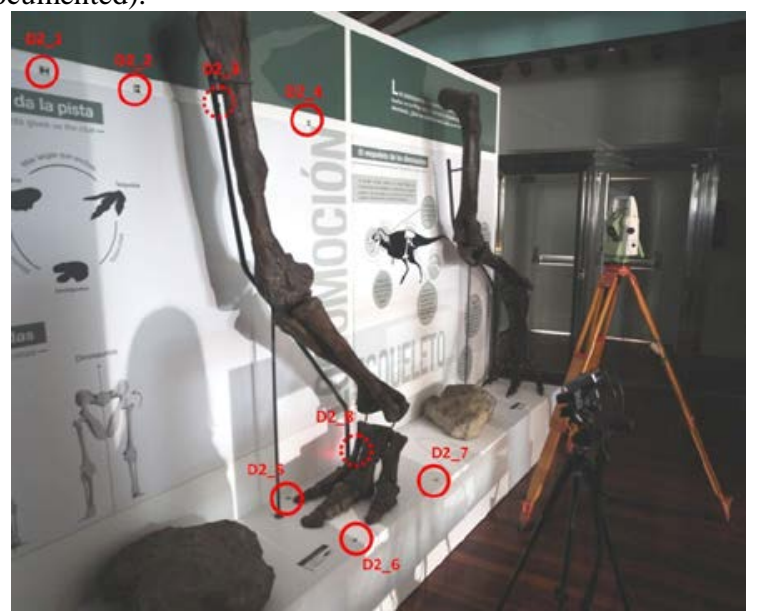

Figure 2. Leg, control points and total station used to provide 3D coordinates.

The photographic record was done with a reflex camera (Canon EOS Mark II) of 20 megapixels and a $21 \mathrm{~mm}$ Zeiss lens. Around 200 photographs were taken trying to cover the bones from all possible viewpoints with enough overlap for the software for 3D image based modelling. A stool was employed to reach the upper part of the femur. The distance from the bones was between $40 \mathrm{~cm}$ and 1 meter.

The 3D model was done with the software Agisoft Photoscan. The resulting point cloud was rather noisy due to the aforementioned bad lighting. After trimming the dense cloud we kept around 10 millions of points (figure 3).
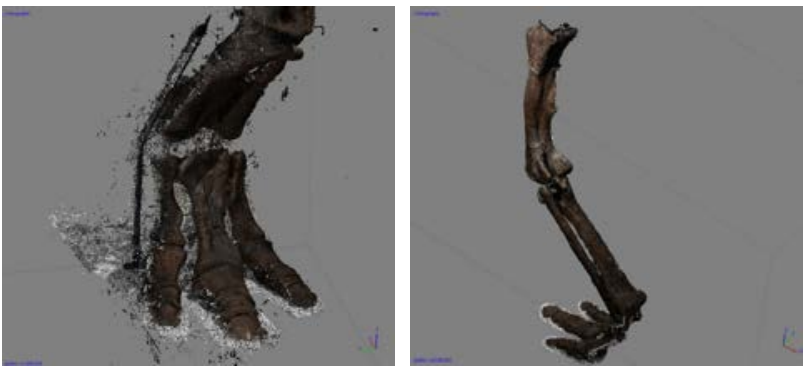

Figure 3. Noisy dense point cloud (left) and model after cleaning (right).

Then the points concerning each bone were individualized for further cleaning. The final cloud showed gaps in the hidden areas that we filled in during the meshing (the software for dynamic studies requires "closed" models). A mesh size of 5 $\mathrm{mm}$ was considered adequate for the final output. Finally, a smoothing filter was applied in order to remove the roughness of the surfaces since this feature is unnecessary for the later analyses (figure 4).

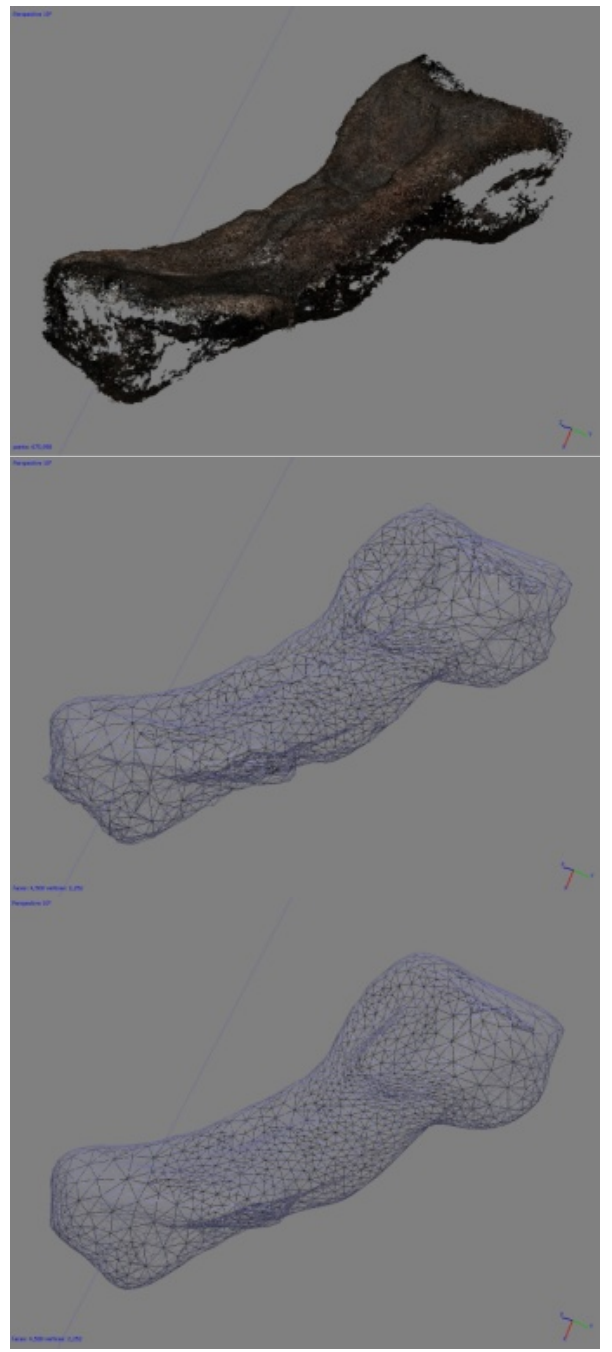

Figure 4.- One of the bones of the foot (a $28 \mathrm{~cm}$ long tarsus). Clean point cloud with gaps (top), mesh with a resolution of around $5 \mathrm{~mm}$, done with extrapolation in order to fill the holes (middle) and smoothed mesh (bottom).

We also used a structured-light 3D scanner, in particular, a "Scan in a Box" model consisting in a projector and two cameras. According to the technical specification of this piece of equipment, the single scanning field ranges from around $10 \mathrm{x}$ $8 \mathrm{~cm}$ up to around $50 \times 40 \mathrm{~cm}$ (with a geometric accuracy of 0.1 $\%)$. Originally, we expected to use this device for scanning the bones individually since the complete piece is out of its range; however, as told before, we could not disassemble the replica so we decided to scan only the fingers (figure 5) and use this 
model for checking the quality of the 3D model generated by photogrammetry. The model of the fingers is composed of 22 scans.

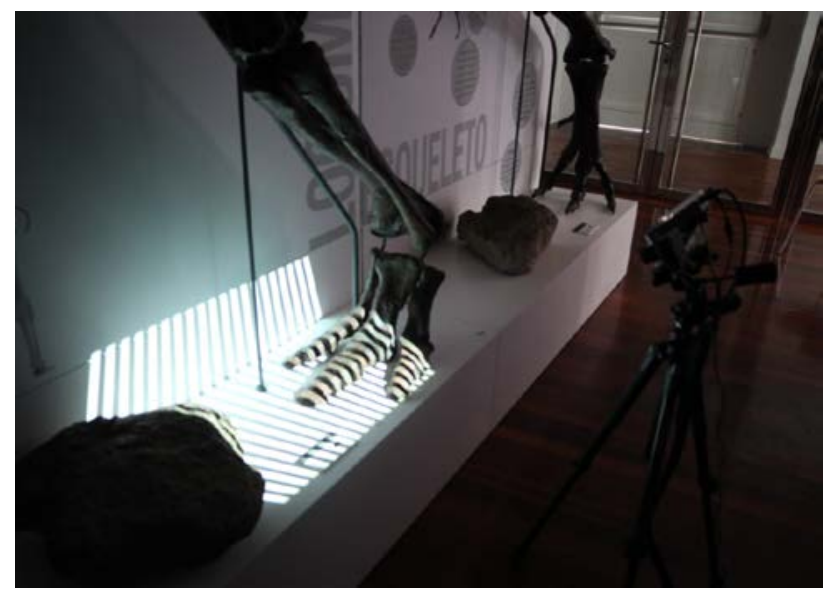

Figure 5.- Fringe projection during the 3D data acquisition with the "Scan in a Box" device.

\section{RESULTS}

Individual natural scale models for each bone were produced, all in the common reference system (the anatomical position that was in the display) so the user can visualize them one by one or by groups (figure 6).

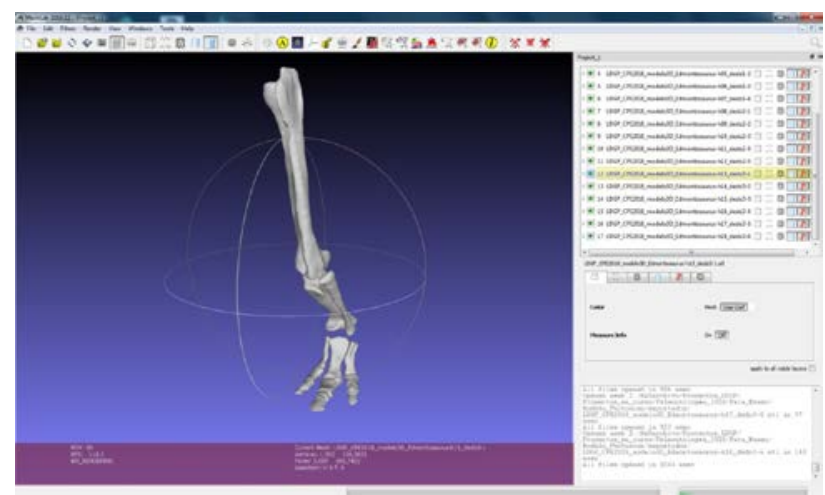

Figure 6.- Individual models of each bone, visualized together in Meshlab.

The output resolution of the bones was established in $5 \mathrm{~mm}$. This size is a weighted value which takes into account the accuracy of the models, the degree of extrapolation and the limits of the software for biomechanical computation (in particular for Finite Elements Analyses). The file format asked for the subsequent software was STL, so the models were exported to that format. The texture of the original elements is not relevant for such analyses.

As for the geometric accuracy of these models, we compared them with the partial model of the fingers obtained with the structured-light scanner ("Scan in a Box"). This comparison was done with the software Cloud Compare (figure 7). In general, the distance between both models is less than $5 \mathrm{~mm}$ with the exception of some protuberances at the end of the bones where, due to the smoothing filter, the discrepancies can reach out to $1 \mathrm{~cm}$.
Obviously, this difference is only valid for the parts of the bones that were documented with both methods. However, we think that it can be indicative for the most part of the models.

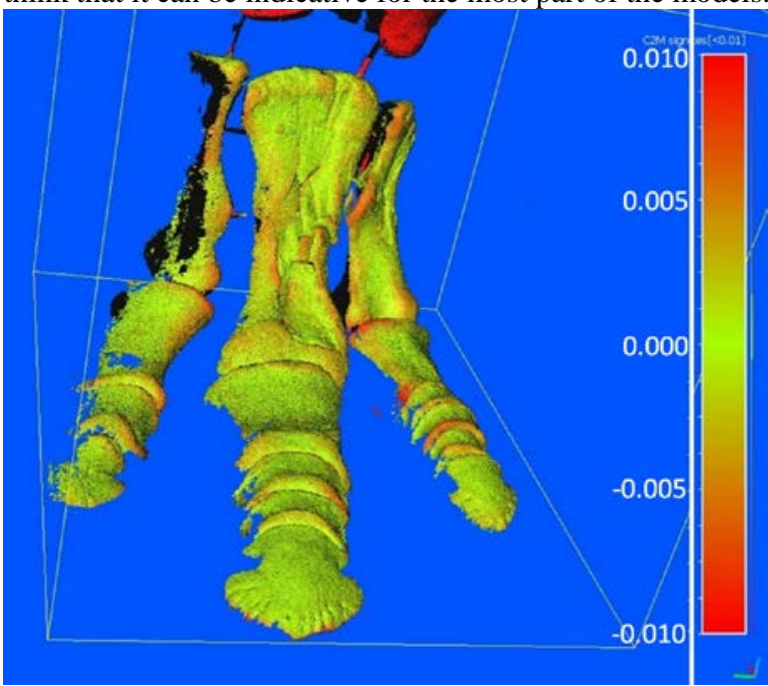

Figure 7.- Distances from the model generated with structured light and the 3D models generated by photogrammety (image in

Cloud Compare). The image shows a colour palette over the structured light model (distances in meters).

This project is part of a series of works aimed at digitizing and updating the information about the paleontological sites and specimens in the area of La Rioja in Spain. An essential axis of this effort is the dissemination of the data and the generation of useful scientific resources that can be re-used worldwide.

In consequence and as a general rule, all the data produced will be freely accessible via web in two complementary platforms. On the one hand, during the last years we are working with the mapping service of the regional government of La Rioja to establish a Standard Data Infrastructure (SDI) of paleontological sites. This Infrastructure will be available within the public catalogue of this cartographic service in several ways: Web Map Service (WMS), Web Feature Service (WFS) and as a stand-alone viewer (Valle et al., 2019). This thematic layer, still under construction but already functional and available, shows the location of the sites and gives access to their descriptive information and related files such as photographs (current and historical ones), videos, sketches... but also three-dimensional models. On the other hand, threedimensional models, together with the details of the documentation, data processing and characteristics of the obtained results will be stored in the university repository, from where they will be freely accessible either directly or through aggregators such as Europeana.

Nevertheless, the aforementioned commitment for the Open Data should be put into the right context in this particular case. Indeed, it will not be any particular problem to publish the 3D models generated from real specimens that are deposited in the local museum but it must be reminded that the 3D models referred in this paper have been generated from commercially distributed replicas, thus, exploitation rights might be still in force. 


\section{DISCUSSION}

Although analyzing the needs and available resources so as to configure the recording methodology and the features of the final products is an established procedure in geometric documentation of cultural heritage, in some cases, neither the aforesaid needs nor the resources are clearly defined beforehand. This is the situation presented in this paper, since the way of reaching to the objective (study of the dinosaurs' footfall action) is highly prospective and still requires the parallel development of several parts apart from the geometric modelling of the fossils remains, in particular, the recreation of the disappeared parts (e.g. soft tissues), the modelling of the forces at play or the adjustment of the FEM model so as to reproduce realistically the response of the ground.

Each one of these pieces will condition the rest of them. In consequence, it might not be possible to previously define a unique way of generating suitable 3D models. Rather, this paper is aimed at testing the possibilities of different techniques, detecting issues and evaluating the results.

So far, we have seen that it is possible to employ convergent photogrammetry and structured-light 3D scanner scanning techniques for fast recording without taking the specimens apart from their display and generating meshed models of each individual bone with a resolution from a few millimetres to centimetres. In general, being able to work with the pieces as they are in the museum will be less expensive and easier to justify since the pieces will be less exposed to risks of deterioration, as well as permanently available for the visitors. Nevertheless, in order to generate complete models, significant parts of the bones were interpolated (something that could have been avoided if we had access to the dismantled pieces); therefore, it is essential to check if these interpolations do not affect the results of the next calculations.

The only way to assess this point is to compare the FEM results with another group of models generated with bones without interpolation. For this reason, at present, new tests are in progress with more specimens in different states, for instance, bones disassembled, but also with bones that are still partially embedded in the rocky substrate.

The average resolution of the 3D models was set to $5 \mathrm{~mm}$, this is a preliminary value that was considered adequate for the FEM analysts taking into account the limits of the software for computation but also considering that the model has to represent the "original" state of the bones (and not the current one) and, hence, many of the details that appear in the real geometry, which are due to the degradation during the fossilization, excavation and storage, have no relevance for the purpose.

Anyway, there is room for tuning up the methodology used for the registration and 3D modelling. Indeed, we estimate that a range of resolutions from $2-3 \mathrm{~mm}$ up to $2-3 \mathrm{~cm}$ (mesh size) could be feasibility attainable with the procedure described above.

Another point that merits a comment is the use of replicas in order to establish the methodology for the geometric documentation before undertaking the work with real pieces. Indeed, although their stony nature, fossils are rather delicate and brittle, they need to be handled with care (Plaza \& Rivas,
2013, Santos et al., 2013), may be bulky and heavy, that is to say, difficult to transport in case we want to document them in an adapted space, for instance a photographic laboratory. Moreover, museums are often reluctant to allow their pieces to go out of their premises and, in any case, removing a piece from a museum can be a complicated matter, which also entails serious legal implications and responsibilities (González, 2013). Concerning the time necessary for the registration, in the case of the Edmontosaurus, the complete data collection including the preparation, measurement of the control points, photographs and scanning of the fingers took around four hours.

We can compare these figures with the following case of another specimen: an Albertosaurus sarcophagus replica, purchased at Triebold Paleontology, Inc. (figure 8), whose bones were scanned individually in a laboratory at the University with the structured-light device. These bones are the replica of the one found in a specimen found in Montana at the Two Medicine Formation in Teton county. Albertosaurus sarcophagus is a tyrannosaurid theropod that lived in North America in the upper Cretaceous (Currie, 2003).

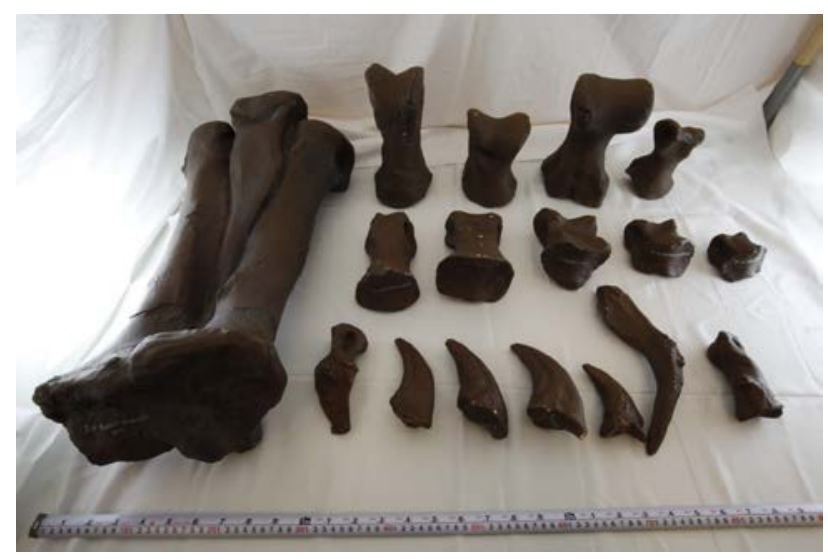

Figure 8.- Set of bones (real size replicas) corresponding to a leg of a specimen of Albertosaurus.

In this case, the time necessary for the recording of each element varied from approximately one hour for the smaller pieces (e.g. the claws), for which, 10-15 scans were necessary, up to the complete day and more than 80 scans that were necessary for the biggest of the bones (around $60 \times 40 \times 20 \mathrm{~cm}$ ). Therefore, it is clear that an exhaustive scanning of a specimen can become very time-consuming compared with the photogrammetric documentation of the mounted one. Besides, let us remember that we are dealing with replicas of the bones that can be handled with freedom, hence, we must expect that times and costs will be greater with real fossils.

The metric of the structured-light scanner is adjusted on site with the calibration plates ensuring sub-millimetric accuracy. Then, the individual models were imported in Cloud Compare and they were virtually mounted, that is to say: moved and rotated in order to relatively place them (figures 9 and 10).

As for the size and resolution of the 3D models, the procedure defined for the Edmontosaurus generated models with a resolution of $5 \mathrm{~mm}$, that gave models of around 20000 meshes for the biggest bones (e.g. femur) and going down to the 500 meshes necessary for the smaller of the phalanges. The initial resolution of the bones scanned in the laboratory was 100 times smaller (in other words: a resolution of $0.5 \mathrm{~mm}$ ). 


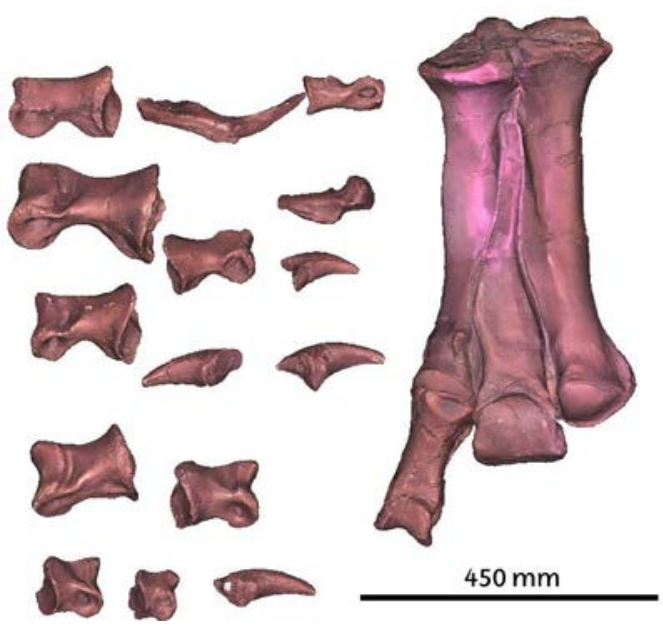

Figure 9.- Virtual assemblage of the bones that form the foot of the specimen of Albertosaurus.

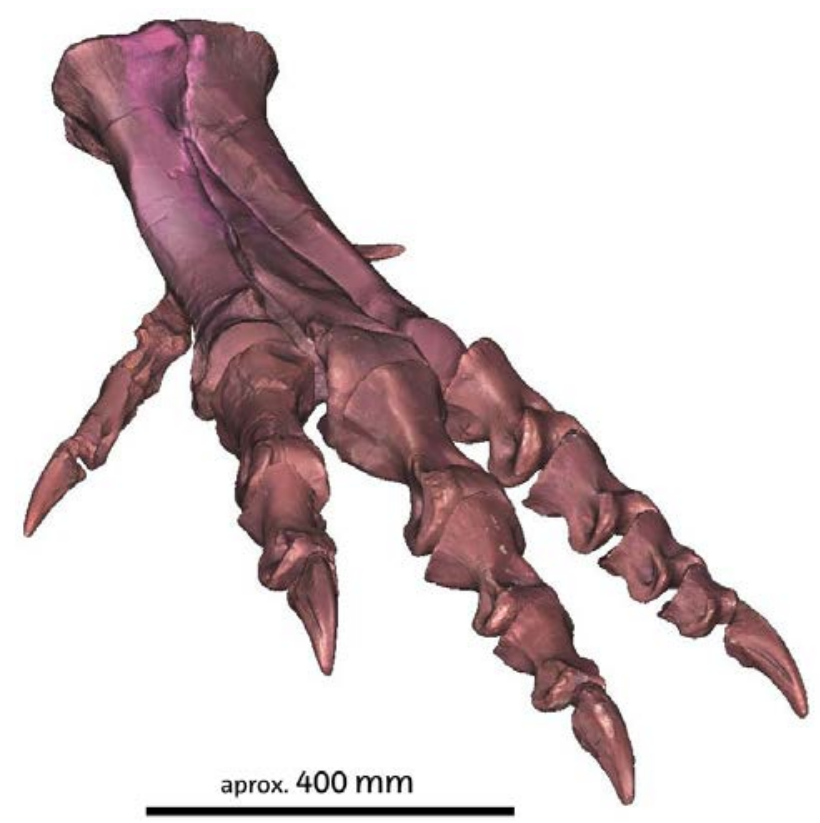

Figure 10.- Final 3D model of the foot of the Albertosaurus in anatomical position.

Summing up, a combined analysis of the methodologies used for both the Edmontosaurus (close range photogrammetry of the bones as they were in the exhibition display) and the Albertosaurus (structured-light scanning in laboratory of the bones one by one) shows that the former case implies a less invasive and faster method that can reach resolutions down to a few millimetres. By contrast, the latter method permits improving the resolution up to submillimetric values but at the cost of a longer and more delicate recording phase.

As said at the beginning of the text, the methodology to be used for the geometric documentation is determined by the desired quality of the products (resolution, accuracy, completeness...) and the available resources. In this article we have reviewed two complementary options for dinosaur bones that might give response to a wide variety of situations.

\section{CONCLUSIONS}

Some ichnites like Iguanodontipus and Caririchnium, present in the Lower Cretaceous of the Iberian Peninsula, are attributed to iguanodontians (Díaz-Martínez, 2011). Taxa included in this clade have a more or less constant body plan: primarily bipedal (although some species could be quadrupedal under certain conditions) with a quite robust hind limb and a relatively stiff foot, with limited movement of the toes especially when compared with another bipedal dinosaurs like theropods, whose feet joints were more mobile. This constant body plan of Iguanodontia, along with the similar size of the possible trackmakers of the Iberian Peninsula ichnites and E. regalis makes this taxon an acceptable candidate to develop a 3D musculoskeletal model applicable to the Lower Cretaceous iguanodontian ichnites. The use of these fossil tracks is important in our biomechanical studies because once the musculoskeletal model is created (bones, muscles, tendons, etc.), the movement of the whole system must be tested, and the only evidences we have of a moving dinosaur are their tracks. Comparison of the real tracks and those generated via software will allow us to test if the movements generated for the model are the adequate or if some variation or modification is required.

When dealing with 3D models for dynamic analyses with FEM, geometric accuracy might not be the main concern. Firstly, because the software has limits regarding the size of the models that can manage, secondly, we need to bear in mind that, after all, the fossils are deteriorate versions of the former bones, therefore, there is no gain in documenting in great detail the current surfaces when we want to produce a model of the "original" shape. On the contrary, what is essential is that the models are topologically correct, that is to say, without holes and located in their proper position.

Although for this work we have selected a common output resolution, it might be advisable to resort to an adapted resolution for each bone according to their size or, even better, a variable resolution for different parts for each single bone. Indeed, there are parts of the bones that may be of little importance for the biomechanical study (for instance the roughness in the central part of a long bone), however, the epiphyses (end part of the bones) may be critical for the result of the computation so an improved resolution might be necessary in these areas. Of course, this multi-resolution criterion will be conditional upon the possibilities to manage models of the software for the subsequent computations.

It is worth also mentioning that the aforementioned critical parts tend to be located in the joints between bones, therefore, when digitizing a model already mounted (as in our case study) they will be hidden in a considerable degree. However, having the bones mounted has the benefit of simplify the orientation of the models since a single group of control points is enough, the problems of different scaling are also avoided.

Hidden parts are another issue, although meshing can alleviate it, to some extent, by interpolation. This problem should not be taken lightly because, in the absence of proper data, the surfaces reconstructed by interpolation might be very different from the original ones. 
From the previous sentences, we can infer that in an ideal case we may need to count on two different digitisations (one general with all the pieces mounted in anatomical order and another composed by a series with each bone free of attachments). Nevertheless, in a real situation it is more reasonable to imagine that we will have to adapt to the way the bones are.

This study stops at the generation of the 3D model of the bone system. From this point on new procedures for completing the body of the animal and the substrate need to be done (some examples: Araujo \& Polcyn, 2013; Cuff et al., 2017).

\section{ACKNOWLEDGEMENTS}

We want to give our thanks to the people in charge of the Paleontological Centre in Enciso for allowing us to use the facilities during the closing hours for the scanning of the bones.

\section{REFERENCES}

Araujo, R.; Polcyn, M.J., 2013. A biomechanical analysis of the skull and adductor chamber muscles in the Late Cretaceous Plesiosaur Libonectes. Palaeontologia Electronica, 16.2.10A., doi.org/10.26879/287.

Cuff, R.; Goswami, A.; Hutchinson, J.R., 2017. Reconstruction of the musculoskeletal system in an extinct lion. Palaeontologia Electronica, 20.2.23A., doi.org/10.26879/688.

Currie, P.J. (2003). Cranial anatomy of tyrannosaurid dinosaurs from the Late Cretaceous of Alberta, Canada. Acta Palaeontologica Polonica, 48(2), pp. 191-226.

Das, A.J.; Murmann, D.C.; Cohrn, K.; Raskar, R., 2017. A method for rapid 3D scanning and replication of large paleontological specimens. PLoS ONE, 12(7): e0179264, doi.org/10.1371/journal.pone.0179264.

Díaz-Martínez, I., 2011. Generalidades sobre las icnitas ornitópodas de La Rioja (Cuenca de Cameros, España). Zubia, 29, pp. 61-84.

Erolin, C.; Jarron, M.; Csetenyi, L. J., 2017. Zoology 3D: creating a digital collection of specimens from the D'Arcy Thompson Zoology Museum. Digital Applications in Archaeology and Cultural Heritage, 7, pp. 51-55, doi.org/10.1016/j.daach.2017.11.002.

Falkingham, P.L., 2012. Acquisition of high resolution threedimensional models using free, open-source, photogrammetric software. Palaeontologia Electronica, 15.1.1T, doi.org/10.26879/264.

González, I., 2013. Tráfico (o manipulación) de bienes culturales: aspectos jurídicos. In: Frágil. Curso sobre manipulación de bienes culturales. Ministerio de Educación Cultura y Deporte (Spain), pp. 54-69.

Gutiérrez-García, J.C.; Gutiérrez-García, T.A.; Mosiño, J.F.; Vázquez-Domínguez, E.; Martínez, A.; Arroyo-Cabrales, J., 2015. A novel application of the white light/fringe projection duo: recovering high precision 3-D images from fossils for the digital preservation of morphology. Palaeontologia Electronica, 18.2.6T, doi.org/10.26879/516.
Lambe, L.M., 1917. A new genus and species of crestless hadrosaur from the Edmonton Formation of Alberta. The Ottawa Naturalist, 31, pp. 65-73.

Mallison, H., 2011. Digitizing methods for paleontology: Applications, benefits and limitations. In: Computational Paleontology, chapter 2. Springer-Verlag Berlin Heidelberg, doi.org/10.1007/978-3-642-16271-8_2.

Marcé-Nogué, J.; Fortuny, J.; Gil, L. ; Sánchez, M., 2015. Improving mesh generation in finite element analysis for functional morphology approaches. Spanish Journal of Palaeontology, 30-1, pp. 117-132.

Molnar, J.L.; Pierce, S.E.; Clack, J.A.; Hutchinson, J.R., 2012. Idealized landmark-based geometric reconstruction of poorly preserved fossil materials: A case study of an early tetrapod vertebra. Palaeontologia Electronica, 15.1.2T, doi.org/10.26879/274.

Norman, D.B., 2004. Basal Iguanodontia. In: Weishampel DB.; Dodson P.; Osmólska H. eds. In: The Dinosauria: Second Edition. Berkeley: University of California Press, pp. 413-437.

Plaza, M.; Rivas, J., 2013. Introducción a la manipulación de los objetos culturales. Profesionales involucrados y su formación. In Frágil. Curso sobre manipulación de bienes culturales. Ministerio de Educación Cultura y Deporte (Spain), pp. 12-23.

Santos, C.; Pérez, P.; Barreiro, J., 2013. Riesgos en la manipulación de colecciones de historia natural. In: Frágil. Curso sobre manipulación de bienes culturales. Ministerio de Educación Cultura y Deporte (Spain), pp. 196-214.

Sereno, P.C., 1986. Phylogeny of the brid-hipped dinosaurs (Order Ornithischia). National Geographic Research, 2, pp. 234-256.

Ugidos Lozano, M.T.; Blaya Haro, F.; Ruggiero, A.; Manzoor, S.; Menendez-Pidal, N.; Juanes Méndez, J.A., 2018. Different digitalization techniques for 3D printing of anatomical pieces. Journal of Medical Systems, 42:46. doi.org/10.1007/s10916018-0903-z.

Valle, J.M.; Rodríguez, Á.; Martínez, R.; Pérez, P.; Uceda, S.; Lopetegi, A., 2017. New metric products, movies, and 3D models from old stereopairs and their application to the in situ palaeontological site of Ambrona. Spanish Journal of Palaeontology, 30, 2, pp. 279-290.

Valle, J.M.; Rodríguez, Á.; Pérez-Lorente, F.; Torices, A., 2019. The use of new web technologies for the analysis, preservation and outreach of paleontological information and its application to La Rioja (Spain) paleontological heritage. $\begin{array}{llr}\text { Palaeontologia } \quad \text { Electronica, 22.1.1T } & 1-10,\end{array}$ doi.org/10.26879/918.

Wiedemann, A.; Suthau, T.; Albertz, J., 1999. Photogrammetric survey of dinosaur skeletons. Mitteilungen aus dem Zoologischen Museum in Berlin, Geowiss. Reihe, 2, pp. 113119. 